\title{
Structural, Thermal and Optical Modifications of Chitosan due to UV-Ozone Irradiation
}

\author{
Nabawia A. Abdel-Zaher ${ }^{1}$, Gehan T. El-Bassyouni ${ }^{2}$, Manal T.H. Moselhey ${ }^{3}$ and \\ Osiris W. Guirguis ${ }^{*}$ \\ ${ }^{1}$ Textile Metrology Lab, National Institute for Standards, Giza, Egypt \\ ${ }^{2}$ Refractories, Ceramics and Building Materials Department, National Research Centre (NRC), \\ Giza, Egypt \\ ${ }^{3}$ Al-Safwa High Institute of Engineering, Cairo, Egypt \\ ${ }^{4}$ Biophysics Department, Faculty of Science, Cairo University, Giza, Egypt
}

\begin{abstract}
$\mathbf{T}$
HE PRESENT work focused on modifying the chitosan structure which has noticeable places in advanced research. The effect of UV-ozone irradiation with different exposure doses $\left(9.68 \times 10^{-14}, 19.35 \times 10^{-14}, 29.03 \times 10^{-14}\right.$ and $\left.38.75 \times 10^{-14} \mathrm{~J} / \mathrm{m}^{2}\right)$ on the microstructural, thermal stability and optical properties of chitosan was studied. X-ray diffraction (XRD), selected area electron diffraction (SAED), high-resolution transmission electron microscopy (HRTEM), optical parameters techniques as well as differential thermal analysis (DTA) and thermogravimetric analysis (TGA and DTG), were performed. The obtained results indicated that, effects on semi-crystalline structures have occurred. Detected variations in XRD, SAED, HRTEM, DTA and TGA analyses under investigation may be attributed to the different degrees of crystallinity, induction of structural changes and molecular configuration of chitosan upon exposure to UV-ozone. The results confirmed that the UV-ozone irradiation plays a role in refining the microstructure and changes occurring in chitosan matrix for future biomedical applications.
\end{abstract}

Keywords: Biodegradable materials, UV-ozone irradiation, Structure configuration, Thermal analyses, Optical parameters.

\section{Introduction}

Extensive research, development and several applications in different industrial and medical fields of biopolymeric materials were supported due to their physical, mechanical, and chemical properties [1]. Chitin and chitosan are of commercial concern because of their high nitrogen content $(6.89 \%)$ and their excellent properties. Chitosan [Poly (1,4-b-Dglucopyranosamine)] represents as a biopolymer, and it is the second abundant polysaccharide found on earth after cellulose [2]. It is synthesized by alkaline N-deacetylation of chitin. Chitosan has two main reactive groups; (1) C-2 free amino groups and (2) hydroxyl groups in the C-3 and C-6 acetylated or deacetylated groups; that can be modified by grafting [3]. Chitosan is biodegradable, bio-functional, and biocompatible with living tissues as well as it has chemical stability, mechanical strength, non-toxic odorless and antimicrobial properties [4,5]. Chitosan and its derivatives have several applications in different fields such as: in biotechnology, improve wound healing in human, drug delivery and competent candidates for preparing composite bone cements [6], as moisturizing and conditioning product in the cosmetics industry [7] and in agriculture and textile industries [8]. Furthermore, it is widely used in pharmaceutical and biomedical fields as natural cationic polymer to produce bandages and sutures $[9,10]$. Because of its amines functional groups, chitosan has a strong bonding ability to various heavy metal ions to support surfaces as adsorption sites [11]. Then, chitosan has a role in waste water treatment for its adsorption to heavy metals [12].

Ultraviolet irradiation may cause structural modifications of polymeric materials due to photo-oxidation process [13]. Moreover, exposure to ozone leads to surface oxidization. Combined

*Corresponding author. Tel.: (+202)01223251345

E-mail address: osiris_wgr@yahoo.com

DOI: 10.21608/EJCHEM.2018.2904.1241

C2017 National Information and Documentation Center (NIDOC) 
decomposition reactions also occurred due to ultraviolet irradiation. UV-ozone irradiation of polymers is used as a standard dry process for the modification of polymeric materials [14]. Due to UV-ozone irradiation, remarkable development was achieved in crystalline quality, optical, electrical and mechanical properties [15]. Degradation phenomenon is an unwanted phenomenon and may arise after exposure to ozone which was controlled by adjusting the exposure time. The effects of different kinds of radiation on chitosan have been studied by many investigators $[16,17]$. UV-ozone irradiation may induce depolymerization of chitosan. Also, the high potential of antibacterial activity was confirmed by exposing chitosan to UV-ozone for different exposure times [18].

In the present work, the effect of UV-ozone radiation with four exposure doses (9.68 x 10-14, $19.35 \times 10-14,29.03 \times 10-14$, and $38.75 \times 10-$ $14 \mathrm{~J} / \mathrm{m}^{2}$ ) on the microstructure, thermal stability and optical properties of chitosan powder were investigated.

\section{Experimental}

In the present work, off-white Shrimp chitosan powder (MMW, Degree of deacetylation > 90\%) and free of E. coli and Salmonella was obtained from Oxford Lab Chem. Mumbai, India. High intensity, low-pressure mercury lamp without outer envelope with wavelength $184.9 \mathrm{~nm}$ model LRF 02971 of 200 watt, 220 volt, (made in Poland) was used as the UV-ozone source and placed in a cubic box of dimensions $60 \times 60 \times$ $60 \mathrm{~cm}$ at National Institute for Standards, Giza, Egypt [18,19]. Atomic oxygen was generated both when molecular oxygen and ozone subjected to $184.9 \mathrm{~nm}\left(1.5 \mathrm{~mW} / \mathrm{cm}^{2}\right)$ and $253.7 \mathrm{~nm}(15 \mathrm{~mW} /$ $\mathrm{cm}^{2}$ ), respectively. The energy of $\mathrm{UV}$-emissions was; $647 \mathrm{~kJ} / \mathrm{mol}$ for $184.9 \mathrm{~nm}$ and $472 \mathrm{~kJ} / \mathrm{mol}$ for $253.7 \mathrm{~nm}$. Chitosan samples were placed around the source at distance $20 \mathrm{~cm}$. Most hydrocarbons and ozone absorb radiation at wavelength 253.7 $\mathrm{nm}$. The chitosan samples under investigation were exposed to UV-ozone for four exposure doses $\left(9.68 \times 10^{-14}, 19.35 \times 10^{-14}, 29.03 \times 10^{-14}\right.$ and $\left.38.75 \times 10^{-14} \mathrm{~J} / \mathrm{m}^{2}\right)$.

The X-ray diffraction (XRD) patterns of unexposed and exposed chitosan samples were obtained by using Empyrean X-ray Diffractometer (PANalytical Inc., Company, The Netherlands) with an anode tube of $\mathrm{CuK}_{\alpha}$ radiation $(\lambda=1.54060$ $\AA)$, operated at $45 \mathrm{kV}$ and $40 \mathrm{~mA}$. The XRD pattern was recorded in the range of the Bragg's angle $(2 \theta)$ from 5 to $75^{\circ}$ at a scanning speed rate of 2 degrees/minute and at room temperature. The crystallographic structure of chitosan samples before and after exposure was carried out by using High-Resolution Transmission Electron Microscopy (HRTEM; JEM 2100, Jeol, Japan).

The thermal properties of the prepared unexposed and exposed chitosan samples were analyzed in the range $25-750{ }^{\circ} \mathrm{C}$ by using Differential Thermogravimetric Analyzer model Schimadzu DTG-60 (Kyoto, Japan) calibrated by calcium oxalate with accuracy of $\pm 1 \%$. The DTA and TGA analyses were performed at the rate of heating of $10^{\circ} \mathrm{C} /$ minute under a nitrogen atmosphere with a flow rate of $30 \mathrm{~mL} /$ minute. The average weight of the dry sample was about $6 \mathrm{mg}$.

The optical reflectance spectra for the prepared chitosan powders before and after exposure to UV-ozone were recorded in the visible region 380-700 nm using a Shimadzu UV/VIS/NIRDouble Beam Spectrophotometer (Japan) with standard illuminant C (1174.83), model V-530, band-width $2.0 \mathrm{~nm}$ and with the accuracy of $\pm 0.05 \%$. The CIE tristimulus reflectance values $\left(\mathrm{x}_{\mathrm{r}}, \mathrm{y}_{\mathrm{r},}\right.$ and $\left.\mathrm{z}_{\mathrm{r}}\right)$ were calculated from the reflectance data according to the CIE Colorimetric System and CIE 1931 2-degree Standard Observer [20]. The CIE color parameters such as; lightness ( $\left.\mathrm{L}^{*}\right)$, color constants $\left(\mathrm{a}^{*}\right.$ and $\left.\mathrm{b}^{*}\right)$, a total color difference $\left(\Delta \mathrm{E}^{*}\right)$, whiteness index $(\mathrm{W})$, chroma $\left(\mathrm{C}^{*}\right)$, and hue angle $(\mathrm{H})$ were also detected. The effect of UV-ozone exposure on the optical parameters such as; absorption coefficient $(\alpha)$, optical band gap energy $\left(\mathrm{E}_{\mathrm{g}}\right)$, extinction coefficient $(\mathrm{K})$ and color strength $(\alpha / \mathrm{S})$ was also determined from the obtained reflectance values.

\section{Results and Discussion}

Figure 1 shows the X-ray diffraction patterns of chitosan powders before and after exposure to UV-ozone for different doses. It is clear that, diffraction peaks were perfectly indexed to chitosan and no impurity peaks were observed in the XRD patterns. The pattern of unexposed peaks positioned at: $2 \theta=10.26^{\circ}$ due to the $(02$ $0)$ plane of chitosan precursor ( $\alpha$-chitin moieties) conforming to the hydrated crystalline structure; $2 \theta=19.65^{\circ}$ due to the $\left(\begin{array}{lll}1 & 1 & 0\end{array}\right)$ plane of $\alpha$-chitin approving the anhydrous crystalline structure; and $2 \theta=22.10^{\circ}$ due to the amorphous structure of chitosan. The d-spacing (in $\AA$ ) of the peaks were recorded in the figure. These observed peaks 
confirm the presence of chitin units in chitosan framework which engenders a statistic copolymer. The crystallinity of chitosan was produced by a large number of amino and hydroxyl groups present in its structure [21]. The obtained result was in agreement with that previously reported by many investigators $[10,17,22,23]$. Also, the crystallinity of the chitosan powder was improved after UV-ozone radiation in comparison with the unexposed type. No remarkable shift in the position of the three distinct peaks was observed. Also, the intensity of the peaks increased by increasing the exposure dose which designates that crystallinity of chitosan has improved. It may be explained that, during exposure there is an energy dissipated in the chitosan polymeric network. This energy dissipation may produce chain scission or radicals which then decayed with the neighboring radicals. Besides, number of a hydrogen bond between chitosan molecules after UV-ozone exposure than the exposed chitosan was formed compared to unexposed chitosan.

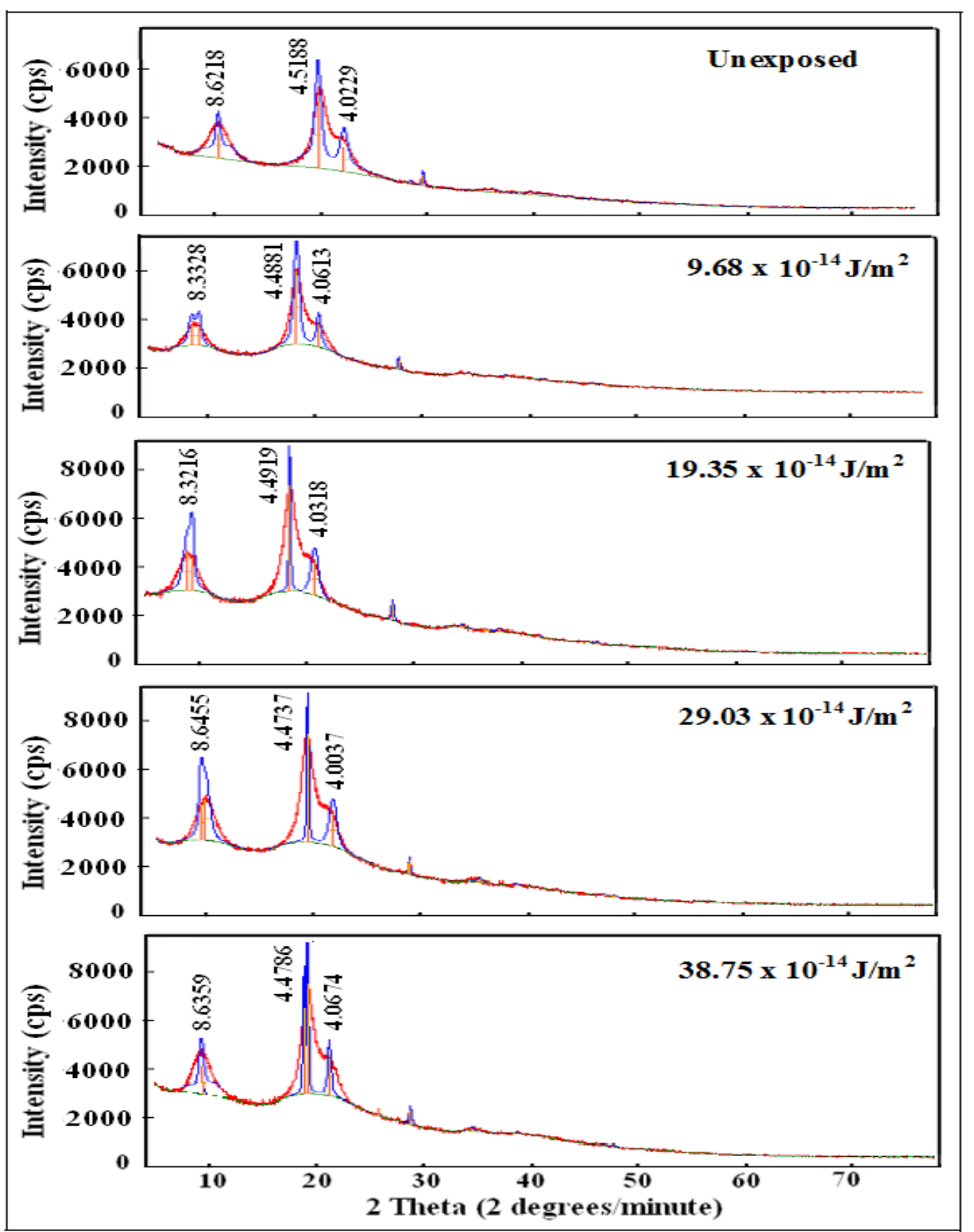

Fig. 1. XRD patterns of chitosan powder before and after exposure to UV-ozone. 
X-ray diffraction was also used to measure the degree of crystallinity (the time-save empirical a measure of relative crystallinity) in polymers [24]. Table 1 represents the variation of the crystallinity index by using the empirical Segal equation: $\left\{\mathrm{CrI}=\left[\left(\mathrm{I}_{\mathrm{f}}-\mathrm{I}_{\mathrm{s}}\right) / \mathrm{I}_{\mathrm{f}}\right] \times 100\right)$, where $\mathrm{I}_{\mathrm{f}}$ and $I_{s}$ are the maximum intensities of the fundamental and secondary peaks, respectively\} with UVozone exposure dose as calculated from the XRD patterns using the two distinguished peaks aligned in the range of $2 \theta=19.85^{\circ}-19.65^{\circ}$ as a fundamental peak and $2 \theta=10.41^{\circ}-9.79^{\circ}$ as a secondary one. The table delineated that, the unexposed chitosan presented the minimum value of crystallinity index and its value improved with increasing the exposure dose. The obtained increase in CrI value noticed that the amorphous of chitosan network decreases due to the effect of UV-ozone irradiation which suggested the dominant presence of the crystalline phase [25].
Selected area electron diffraction and highresolution transmission electron microscope were used to describe the morphology, composition, and crystal structure of materials [26,27]. Figure 2 illustrated the SAED patterns of chitosan powder before and after exposure to UV-ozone for 19.35 x $10^{-14}$ and $38.75 \times 10^{-14} \mathrm{~J} / \mathrm{m}^{2}$ exposure doses. The pattern gave clear diffraction rings composed of spots suggesting that the unexposed chitosan powder had semi-crystalline shape which increases with increasing the exposure dose up to $38.75 \times 10^{-14} \mathrm{~J} / \mathrm{m}^{2}$. The HRTEM images of the unexposed and exposed chitosan powder to different doses were taken to investigate their average size and shape as presented in Fig. 3. The obtained results are consistent with the data of $\mathrm{XRD}$ and confirmed that unexposed chitosan had less ordered arrangement compared with those of the exposed samples.

TABLE 1. Variation in crystallinity index (CrI) and its percentage change of chitosan powder before and after exposure to UV-ozone.

\begin{tabular}{ccc}
\hline Exposure dose $\left(\mathbf{J} / \mathbf{m}^{2}\right)$ & Crystallinity index $(\mathbf{C r I})$ & $\Delta(\mathbf{C r I}) \%$ \\
\hline Unexposed chitosan & 63.1996 & - \\
$9.68 \times 10^{-14}$ & 67.5749 & 6.9 \\
$19.35 \times 10^{-14}$ & 65.4260 & 3.5 \\
$29.03 \times 10^{-14}$ & 64.5819 & 2.2 \\
$38.75 \times 10^{-14}$ & 72.8670 & 15.3 \\
\hline
\end{tabular}

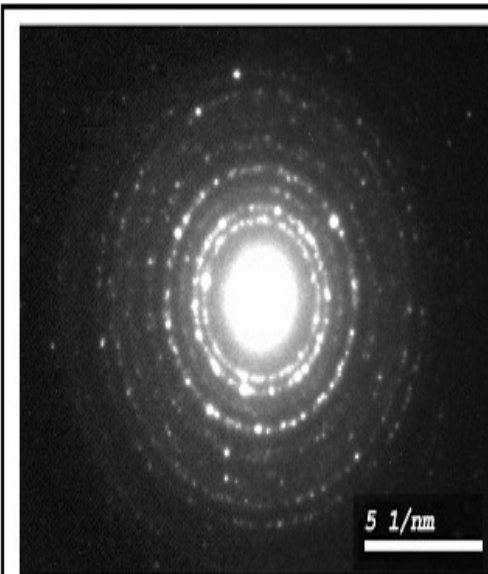

Unexposed chitosan

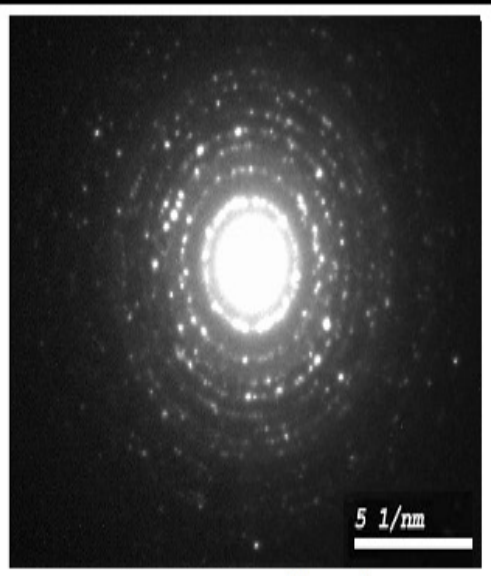

$19.35 \times 10^{-14} \mathrm{~J} / \mathrm{m}^{2}$

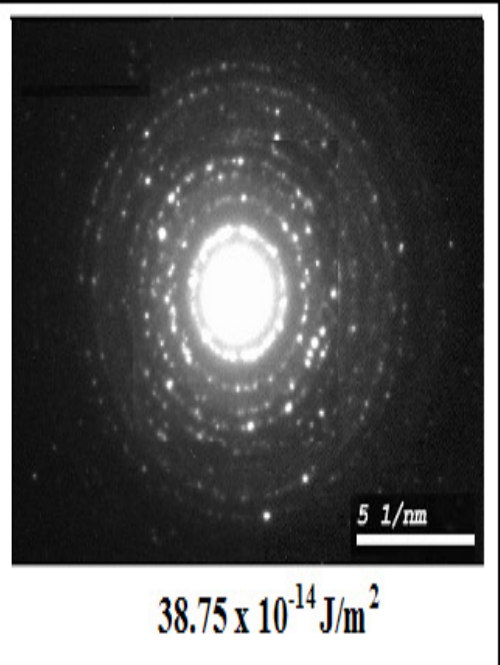

$38.75 \times 10^{-14} \mathrm{~J} / \mathrm{m}^{2}$

Fig. 2. SAED patterns for chitosan powder before and after exposure to UV-ozone. 


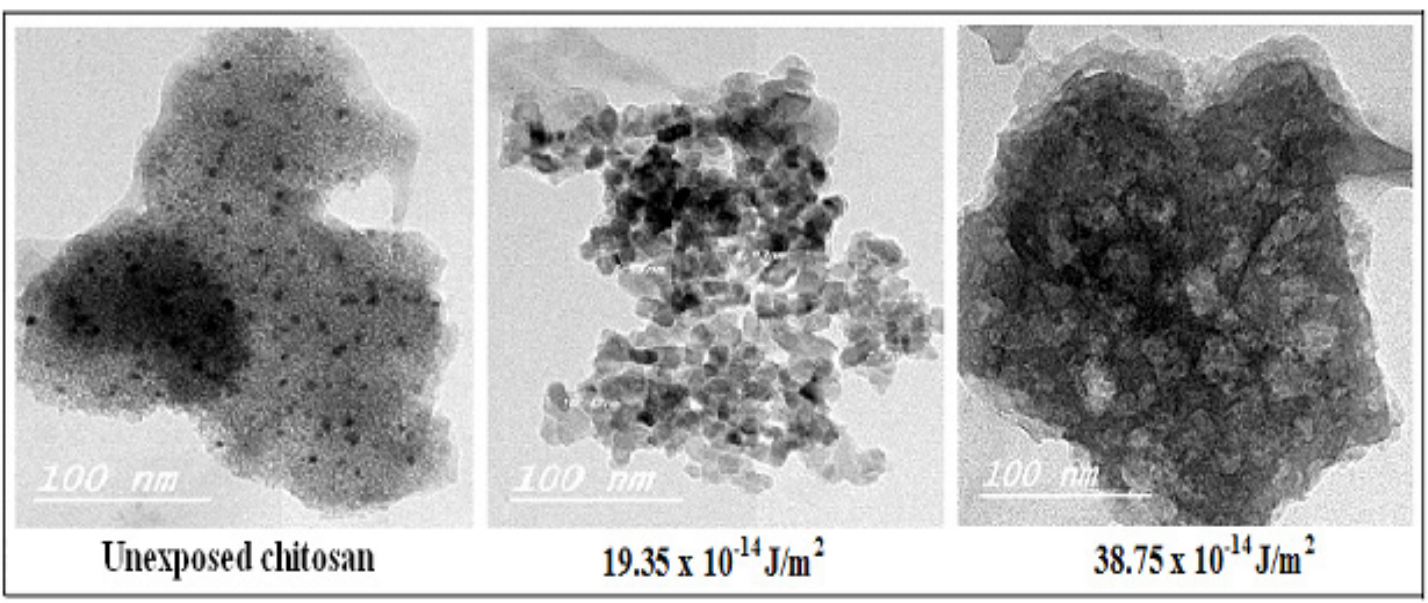

Fig. 3. HRTEM images of chitosan powder before and after exposure to UV-ozone.

The glass transition temperature, the heat of crystallization, melting temperature and heat of fusion were thermal parameters which can be detected by studying the thermal analyses curves [28] such as; DTA, TGA and DTG. Figure 4 shows the DTA curves of chitosan powder before and after being exposed to UV-ozone. Table 2 records two transition temperatures $\left(T_{1}\right.$ and $T_{2}$, respectively) and the heat of fusion values $(\Delta \mathrm{H})$ for each transition detected from the unexposed and exposed chitosan plots. It was noticed that, the DTA thermograms of all samples display two decomposition stages which indicate the existence of more than one decomposition process. The first stage, $<100^{\circ} \mathrm{C}$, represents the first order thermodynamic transition which may be due to evaporation of physisorbed water from the sample [29]. The endothermic peaks addressed at about 60 and $63^{\circ} \mathrm{C}$ before and after exposure of chitosan powder were detected, respectively. The second process (degradation process) starting at about $210{ }^{\circ} \mathrm{C}$ represents the phase transition temperature in the melting transition region and shows exothermic peaks centered at approximately 307 ${ }^{\circ} \mathrm{C}$ before and after exposure of chitosan powder. This phase transition may be due to the relaxation of the chain segments in the amorphous portion and decomposition of chitosan [29]. Besides, differences in shape and area of the first transition endotherms and melting exotherms peaks after exposure dose up to $38.75 \times 10^{-14} \mathrm{~J} / \mathrm{m}^{2}$ were also observed. Furthermore, no remarkable changes in the values of transition temperatures of the exposed samples were detected while the amounts of heat of fusion decrease with increasing the exposure dose up to $29.03 \times 10^{-14} \mathrm{~J} / \mathrm{m}^{2}$ and then increased while still lower than the unexposed one. These observations indicate that variation in crystal structure was created which may cause reduction in the heat of fusion of the phase change and are in good agreement with the DTA results previously reported $[23,29]$.

Figure 5 illustrates the TGA and DTG curves for chitosan powder before and after exposure to UV-ozone for different doses. The figure displayed that, there are two degradation stages in the TGA curve of all samples which prove the existence of more than one decomposition process. Table 3 represents the variations of the $\%$ weight loss and the transition temperatures (Table $3 \mathrm{a}$ ) as well as the total \% weight loss, the total residue and its percentage change (Table $3 b)$ before and after exposure of chitosan powder for the two decomposition regions. Figure 5 and Table $3 \mathrm{a}$ elucidated that, the first decomposition stage starting at about $25{ }^{\circ} \mathrm{C}$ was followed by thermal stability up to about $210^{\circ} \mathrm{C}$. It shows low values of $\%$ weight loss varies from about $11 \%$ for unexposed to about $7 \%$ for the exposed samples due to the moisture evaporation and depends on the initial moisture content of the powder $[17,23]$. When chitosan powder was heated above $60{ }^{\circ} \mathrm{C}$, a rapid chain elimination of water has begun. The second decomposition stage represents the main region of decomposition as it covered a wider temperature range from about 200 to 750 ${ }^{\circ} \mathrm{C}$ which may be due to the degradation process. It could be characterized by the presence of melting exotherm at about $302{ }^{\circ} \mathrm{C}$. Dramatic weight loss \% was detected; it varied between 51 and $48 \%$ of the unexposed and the exposed 


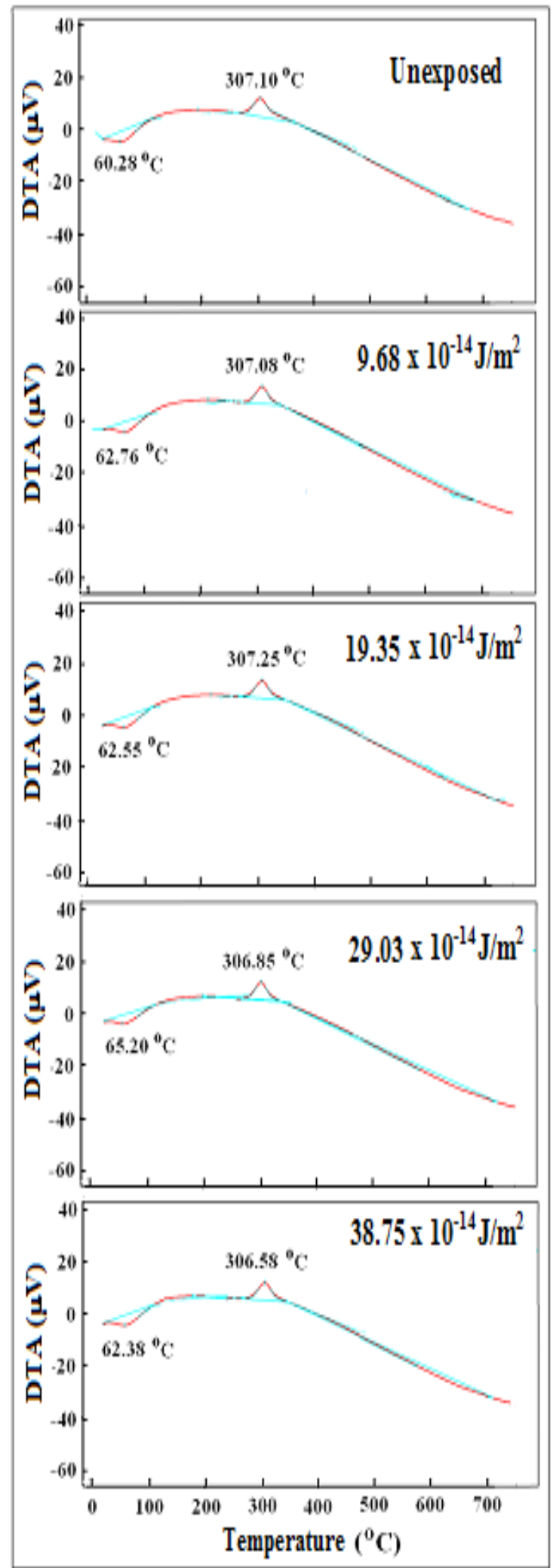

Fig. 4. DTA curves for unexposed and exposed chitosan powder.

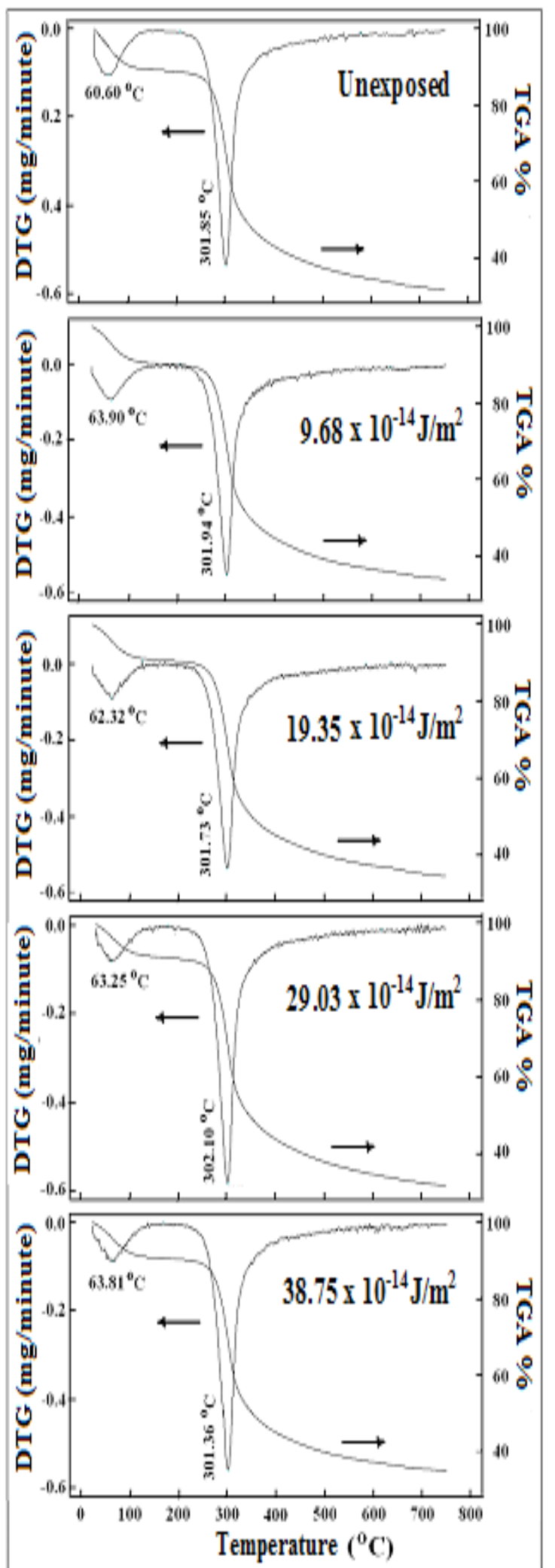

Fig. 5. TGA and DTG curves for unexposed and exposed chitosan powder. 
TABLE 2. DTA data of chitosan powder before and after exposure to UV-ozone.

\begin{tabular}{|c|c|c|c|c|}
\hline \multirow{2}{*}{ Exposure dose $\left(\mathrm{J} / \mathbf{m}^{2}\right)$} & \multicolumn{2}{|c|}{$\begin{array}{l}\text { First order thermodynamic } \\
\text { transition region (First stage) }\end{array}$} & \multicolumn{2}{|c|}{$\begin{array}{l}\text { Melting transition region } \\
\text { (Second stage) }\end{array}$} \\
\hline & $\mathrm{T}_{1}\left({ }^{\circ} \mathrm{C}\right)$ & $\Delta H(J / g)$ & $\mathrm{T}_{2}\left({ }^{\circ} \mathrm{C}\right)$ & $\Delta \mathrm{H}(\mathrm{J} / \mathrm{g})$ \\
\hline Unexposed chitosan & 60.28 & -191.31 & 307.10 & 263.29 \\
\hline $9.68 \times 10^{-14}$ & 62.76 & -200.96 & 307.08 & 206.09 \\
\hline $19.35 \times 10^{-14}$ & 62.55 & -172.39 & 307.25 & 173.85 \\
\hline $29.03 \times 10^{-14}$ & 62.50 & -170.22 & 306.85 & 171.43 \\
\hline $38.75 \times 10^{-14}$ & 62.38 & -95.52 & 306.58 & 204.53 \\
\hline
\end{tabular}

TABLE 3. TGA and DTG data for unexposed and exposed chitosan powder to UV-ozone.

(a)

\begin{tabular}{|c|c|c|c|c|}
\hline \multirow{2}{*}{$\begin{array}{l}\text { Exposure dose } \\
\qquad\left(\mathrm{J} / \mathbf{m}^{2}\right)\end{array}$} & \multicolumn{2}{|c|}{$\begin{array}{l}\text { First order thermodynamic transition } \\
\text { region (First stage) }\end{array}$} & \multicolumn{2}{|c|}{$\begin{array}{l}\text { Melting transition region } \\
\text { (Second stage) }\end{array}$} \\
\hline & $\begin{array}{l}\text { \% weight } \\
\text { loss }\end{array}$ & $\begin{array}{c}\text { Peak temperature } \\
\left({ }^{\circ} \mathbf{C}\right)\end{array}$ & $\begin{array}{l}\% \text { weight } \\
\text { loss }\end{array}$ & $\begin{array}{l}\text { Peak temperature } \\
\text { point }\left({ }^{\circ} \mathrm{C}\right)\end{array}$ \\
\hline Unexposed chitosan & 10.685 & 60.60 & 51.485 & 301.85 \\
\hline $9.68 \times 10^{-14}$ & 9.413 & 63.90 & 51.038 & 301.94 \\
\hline $19.35 \times 10^{-14}$ & 8.579 & 62.32 & 47.867 & 301.73 \\
\hline $29.03 \times 10^{-14}$ & 7.272 & 63.25 & 50.394 & 302.10 \\
\hline $38.75 \times 10^{-14}$ & 9.315 & 63.81 & 48.856 & 301.36 \\
\hline \multicolumn{5}{|l|}{ (b) } \\
\hline $\begin{array}{l}\text { Exposure dose } \\
\qquad\left(J / \mathbf{m}^{2}\right)\end{array}$ & \multicolumn{2}{|c|}{ Total \% weight loss } & Total residue & $\Delta($ total residue $) \%$ \\
\hline Unexposed chitosan & \multicolumn{2}{|c|}{62.170} & 37.830 & - \\
\hline $9.68 \times 10^{-14}$ & \multicolumn{2}{|c|}{60.451} & 39.549 & 4.5 \\
\hline $19.35 \times 10^{-14}$ & \multicolumn{2}{|c|}{56.446} & 43.554 & 15.1 \\
\hline $29.03 \times 10^{-14}$ & \multicolumn{2}{|c|}{57.666} & 42.334 & 11.9 \\
\hline $38.75 \times 10^{-14}$ & \multicolumn{2}{|c|}{58.987} & 41.013 & 8.4 \\
\hline
\end{tabular}

chitosan samples. The DTG plots of unexposed and exposed chitosan powder before and after UV-ozone irradiation evidently witnessed the difference in thermal decomposition behaviors of the samples. The peak temperature values corresponding to the decomposition steps were detected. However, no variations in the values of the peak temperatures were detected between the unexposed and exposed chitosan up to $38.75 \times 10^{-}$ ${ }^{14} \mathrm{~J} / \mathrm{m}^{2}$. This is in consistent with that previously reported $[17,23]$.

Table $3 \mathrm{~b}$ presented that, at the end of the thermal decompositions, the total $\%$ weight loss decreased by exposure to UV-ozone for $9.68 \mathrm{x}$ $10^{-14}$ and $19.35 \times 10^{-14} \mathrm{~J} / \mathrm{m}^{2}$ and then increased by increasing the exposure dose up to $38.75 \times 10^{-14} \mathrm{~J} /$ $\mathrm{m}^{2}$ but was lower than that of the unexposed value. This means that the values of the total residue of the exposed samples were higher than that of the unexposed one [total residue $=\mathrm{W}_{1}-\mathrm{W}_{2}$, where $\mathrm{W}_{1}$ is the total weight of the sample $(100 \%)$ at the starting thermal process and $\mathrm{W}_{2}$ is the total weight loss at the end process]. The attained data indicated that the thermal stability of the two exposed chitosan samples $\left(9.68 \times 10^{-14}\right.$ and $19.35 \times 10^{-14} \mathrm{~J} /$ $\mathrm{m}^{2}$ ) improved and they were more resistant than that of the other higher doses $\left(29.03 \times 10^{-14} \mathrm{~J} / \mathrm{m}^{2}\right.$ and $38.75 \times 10^{-14} \mathrm{~J} / \mathrm{m}^{2}$ ) to fire hazards.

Figure 6 shows the reflectance spectra of chitosan powder before and after exposure to UV- 
ozone in the visible range from 380 to $700 \mathrm{~nm}$. It was clear from the spectra that, the reflectance values increase with increasing the exposure dose up to $19.35 \times 10^{-14} \mathrm{~J} / \mathrm{m}^{2}$ and then decrease by increasing the exposure doses $29.03 \times 10^{-14}$ and $38.75 \times 10^{-14} \mathrm{~J} / \mathrm{m}^{2}$. The observed variations in reflectance values may be due to modification in molecular structure introduced as a result of the degradation/cross-linked process [30]. The tristimulus reflectance values $\left(\mathrm{x}_{\mathrm{r}}, \mathrm{y}_{\mathrm{r}}\right.$, and $\left.\mathrm{z}_{\mathrm{r}}\right)$ of unexposed and exposed chitosan samples were determined from the reflectance values and were plotted as shown in Figure 7. It was noticed that, the behaviors of $x_{r}, y_{r}$, and $z_{r}$ of all chitosan samples were similar and no shift in peak positions was detected. Also, the tristimulus values increase with increasing the exposure dose. Table 4 a and $\mathrm{b}$ represents the values of $\mathrm{x}_{\mathrm{r}}, \mathrm{y}_{\mathrm{r}}$ and $\mathrm{z}_{\mathrm{r}}$ and their percentage changes, respectively, at their peak positions for unexposed and exposed chitosan samples. The observed changes in the $x_{r}, y_{r}$, and $\mathrm{z}_{\mathrm{r}}$ values indicate that variations in the molecular structure of chitosan due to the formation of new color centers were produced [31,32].

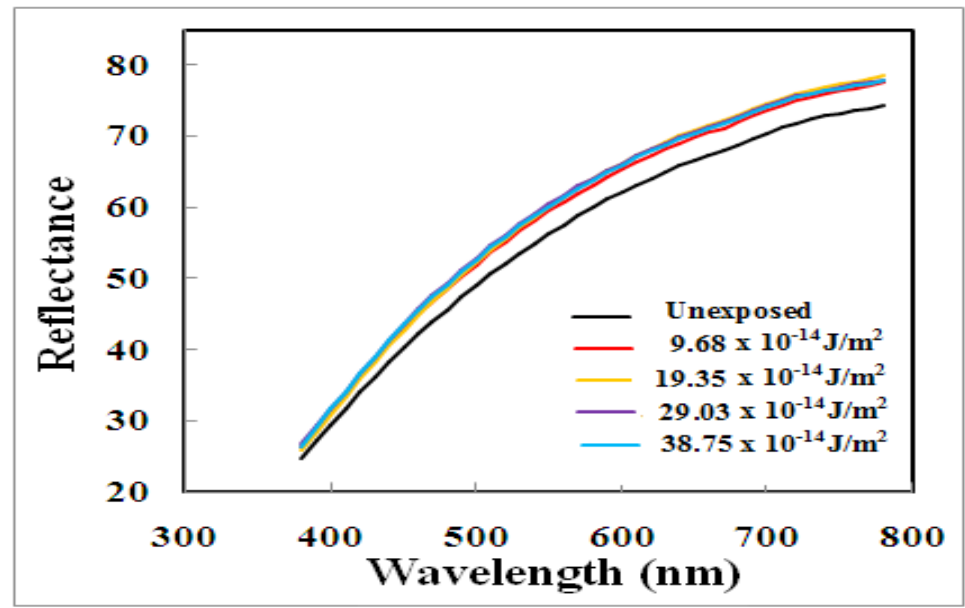

Fig. 6. The reflectance spectra in the visible region of chitosan powder before and after exposure to UV-ozone.
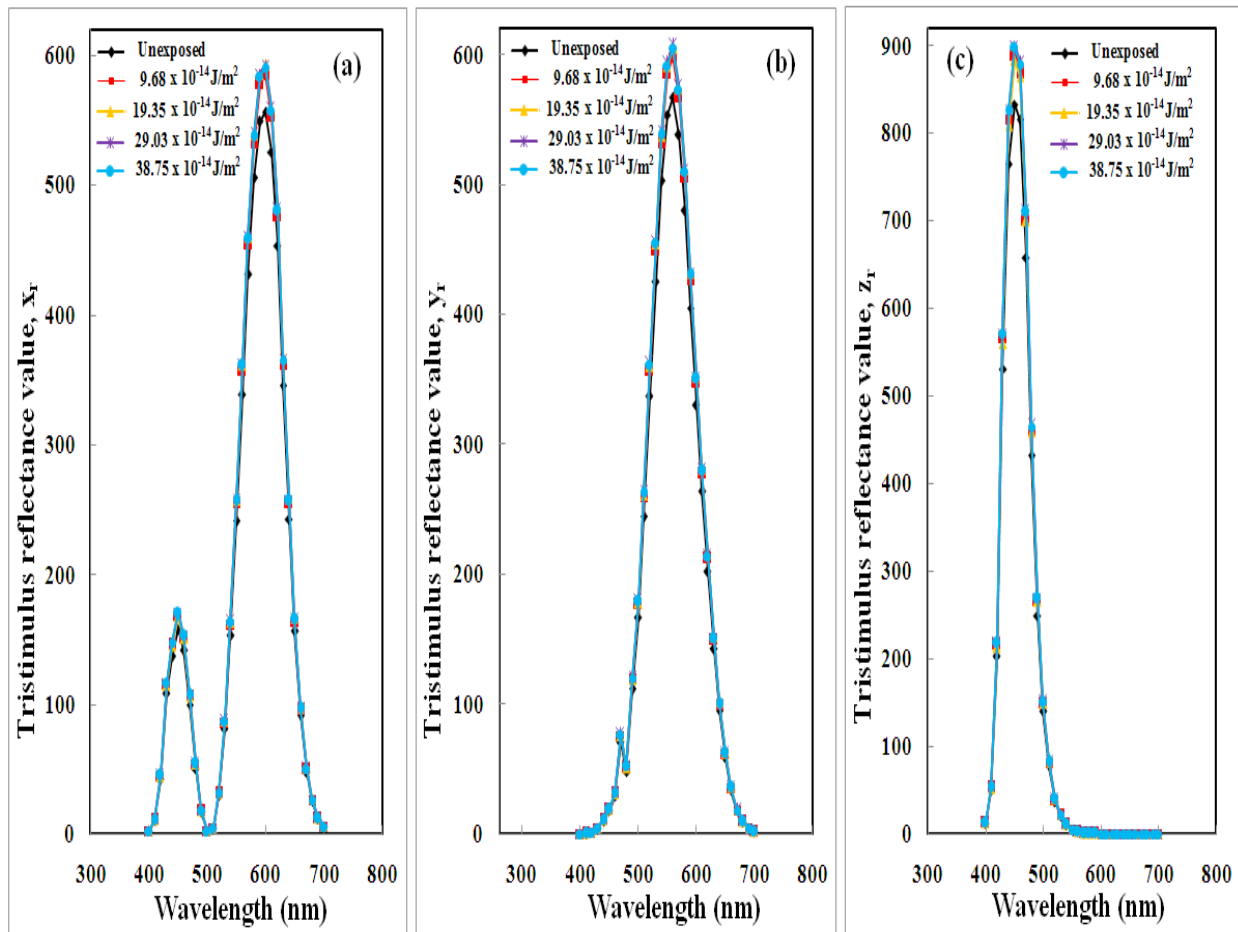

Fig. 7. Variations of tristimulus reflectance values: (a) $\mathrm{xr}$, (b) $\mathrm{yr}$ and (c) $\mathrm{zr}$, with wavelength of chitosan powder before and after exposure to UV-ozone.

Egypt. J. Chem. 61, No.3 (2018) 
TABLE 4. Variations in tristimulus reflectance values $\left(x_{r}, y_{r}\right.$ and $\left.z_{r}\right)$ (a) and their percentage changes $\left(\Delta x_{r}, \Delta y_{r}\right.$ and $\left.\Delta z_{r}\right)(b)$, at their peak positions of chitosan powder before and after exposure to UV-ozone.

(a)

\begin{tabular}{|c|c|c|c|c|}
\hline \multirow{2}{*}{$\begin{array}{c}\text { Exposure dose } \\
\qquad\left(\mathrm{J} / \mathbf{m}^{2}\right)\end{array}$} & \multicolumn{2}{|c|}{$\mathbf{x}_{\mathrm{r}}$} & \multirow{2}{*}{$\frac{y_{\mathrm{r}}}{\lambda=560 \mathrm{~nm}}$} & \multirow{2}{*}{$\frac{\mathrm{z}_{\mathrm{r}}}{\lambda=450 \mathrm{~nm}}$} \\
\hline & $\lambda=450 \mathrm{~nm}$ & $\lambda=600 \mathrm{~nm}$ & & \\
\hline Unexposed chitosan & 158.076 & 556.389 & 566.961 & 833.298 \\
\hline $9.68 \times 10^{-14}$ & 168.668 & 584.914 & 598.388 & 889.134 \\
\hline $19.35 \times 10^{-14}$ & 167.510 & 592.867 & 605.135 & 883.033 \\
\hline $29.03 \times 10^{-14}$ & 170.903 & 593.094 & 607.898 & 900.916 \\
\hline $38.75 \times 10^{-14}$ & 170.568 & 590.794 & 605.212 & 899.153 \\
\hline \multicolumn{5}{|l|}{ (b) } \\
\hline \multirow{2}{*}{$\begin{array}{c}\text { Exposure dose } \\
\left(J / \mathbf{m}^{2}\right)\end{array}$} & \multicolumn{2}{|c|}{$\left(\Delta x_{r}\right) \%$} & $\left(\Delta y_{r}\right) \%$ & $\left(\Delta z_{r}\right) \%$ \\
\hline & $\lambda=450 \mathrm{~nm}$ & $\lambda=600 \mathrm{~nm}$ & $\lambda=560 \mathrm{~nm}$ & $\lambda=450 \mathrm{~nm}$ \\
\hline Unexposed chitosan & - & - & - & - \\
\hline $9.68 \times 10^{-14}$ & 6.70 & 5.13 & 5.54 & 6.70 \\
\hline $19.35 \times 10^{-14}$ & 5.97 & 6.56 & 6.73 & 5.97 \\
\hline $29.03 \times 10^{-14}$ & 8.11 & 6.60 & 7.22 & 8.11 \\
\hline $38.75 \times 10^{-14}$ & 7.90 & 6.18 & 6.75 & 7.90 \\
\hline
\end{tabular}

The CIE color parameters $\left(\mathrm{L}^{*}, \mathrm{a}^{*}, \mathrm{~b}^{*}, \Delta \mathrm{E}^{*}, \mathrm{~W}\right.$, $\mathrm{C}^{*}$, and $\mathrm{H}$ ) of the unexposed and exposed chitosan samples and their percentage changes were calculated according to the formulae reported in the literature $[20,32]$ and presented in Table 5. The table demarcated that: The lightness $\left(\mathrm{L}^{*}\right)$ values increased with increasing the exposure doses up to $38.75 \times 10^{-14} \mathrm{~J} / \mathrm{m}^{2}$ which mean that the colour of chitosan powder became fader. The values of the color constant $\left(\mathrm{a}^{*}\right)$ [red-green components] decrease reached maximum value (13\%) for UVozone exposed sample to $38.75 \times 10^{-14} \mathrm{~J} / \mathrm{m}^{2}$ which indicated that there was an increase in the green component instead of the red one after exposure to
UV-ozone. No remarkable change in the values of the color constant $\left(b^{*}\right)$ [yellow-blue components] was detected. The total color difference $\left(\Delta \mathrm{E}^{*}\right)$ of chitosan sample exposed to $29.03 \times 10^{-14} \mathrm{~J} / \mathrm{m}^{2}$ is the highest dose compared to the other exposed samples. The whiteness index (W) values increase with increasing the exposure dose up to $38.75 \mathrm{x}$ $10^{-14} \mathrm{~J} / \mathrm{m}^{2}$. Nearly no variations in the chroma $\left(\mathrm{C}^{*}\right)$ and hue $(\mathrm{H})$ values were observed. The obtained results indicate that variations in colour difference occurred due to the exposure to UV-ozone of chitosan powder which means that changes in the physical bonds as well as in the molecular configuration of chitosan were occurred [30-32].

TABLE 5. Variations in color parameters and their percentage changes of chitosan powder before and after exposure to UV-ozone.

\begin{tabular}{|c|c|c|c|c|c|}
\hline \multirow{3}{*}{ Colour parameters } & \multicolumn{5}{|c|}{ Chitosan samples } \\
\hline & \multirow{2}{*}{$\begin{array}{c}\text { Unexposed } \\
\text { chitosan }\end{array}$} & \multicolumn{4}{|c|}{ Exposure dose $\left(\mathrm{J} / \mathrm{m}^{2}\right)$} \\
\hline & & $9.68 \times 10^{-14}$ & $19.35 \times 10^{-14}$ & $29.03 \times 10^{-14}$ & $38.75 \times 10^{-14}$ \\
\hline $\mathrm{L}^{*}$ & 79.55 & 81.29 & 81.61 & 81.80 & 81.66 \\
\hline$\left(\Delta \mathrm{L}^{*}\right) \%$ & - & 2.2 & 2.6 & 2.8 & 2.65 \\
\hline$a^{*}$ & 2.31 & 2.14 & 2.16 & 2.04 & 2.01 \\
\hline$\left(\Delta \mathrm{a}^{*}\right) \%$ & - & -7.4 & -6.5 & -11.7 & -13.0 \\
\hline $\mathrm{b}^{*}$ & 16.67 & 16.51 & 16.33 & 16.68 & 16.55 \\
\hline$\left(\Delta \mathrm{b}^{*}\right) \%$ & - & -1.0 & -2.0 & 0.6 & -0.7 \\
\hline$\Delta \mathrm{E}^{*}$ & - & 1.75 & 2.17 & 2.26 & 2.13 \\
\hline $\mathrm{W}$ & -31.20 & -25.80 & -26.10 & -25.40 & -25.00 \\
\hline$\Delta \mathrm{W} \%$ & - & 17.3 & 16.4 & 18.6 & 19.87 \\
\hline $\mathrm{C}^{*}$ & 16.83 & 16.65 & 16.47 & 16.79 & 16.67 \\
\hline$\left(\Delta \mathrm{C}^{*}\right) \%$ & - & -1.1 & 2.1 & -0.24 & -1.0 \\
\hline $\mathrm{H}$ & 82.11 & 82.63 & 82.89 & 83.38 & 83.07 \\
\hline$(\Delta \mathrm{H}) \%$ & - & 0.6 & 1.0 & 1.2 & 1.2 \\
\hline
\end{tabular}


The absorption coefficient [33,34] of chitosan samples $\left\{\alpha=(1 / \mathrm{d}) \ln \left[(1-\mathrm{R})^{2} / \mathrm{T}\right]\right.$, where $\mathrm{d}$ is the thickness of the sample $(\approx 0.1 \mathrm{~cm})$, $\mathrm{T}$ is the transmittance $\left(\approx 10^{-3}\right)$ and $\mathrm{R}$ is the reflectance $\}$ was detected. Figure 8 illustrates the dependence of the absorption coefficient on the wavelength for unexposed and exposed samples. It was clear that the absorption coefficient values decreased with increasing the wavelength and the exposure dose up to $38.75 \times 10^{-14} \mathrm{~J} / \mathrm{m}^{2}$. This reduction may be a reason for the modification in molecular structure introduced as a result of the degradation/cross-

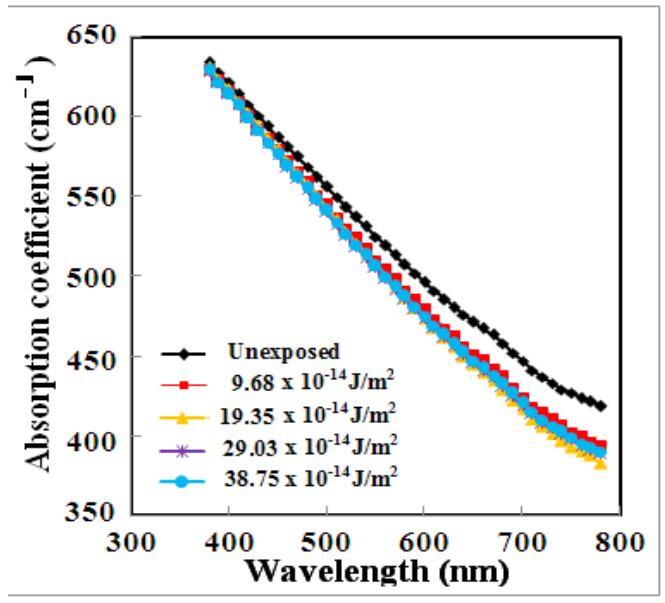

Fig. 8. Plots of absorption coefficient against wavelength of chitosan powder before and after exposure to UV-ozone.

The optical energy gap $\left(\mathrm{E}_{\mathrm{g}}\right)$ was deduced from the absorption coefficient data following Tauc's formula $[33,35]: \alpha h v=B\left(h v-E_{g}\right)^{n}$, where B is the band tail parameter has a value in the range $10^{5}-10^{6}(\mathrm{~cm} . \mathrm{eV})^{-1}$ which is given from the slope of Tauc's edge and $\mathrm{n}$ is the electronic transition responsible type for absorption $(=1 / 2$ of the allowed direct transitions or $=2$ of the allowed indirect transitions). Figure 10 displayed the variation of $(\alpha h v)^{2}$ with $h v$ for unexposed and exposed samples. The allowed direct energy gap $\left(E_{d}\right)$ values and their percentage changes were calculated by extending the linear parts of the curves to zero absorption and were recorded in Table 6. It was observed that, $E_{d}$ values decrease with increasing the exposure dose by about $8 \%$ of all exposed samples. Such reduction indicated that localized states in the band gap were created due to exposure to UV-ozone for different doses. Figure 11 showed the change of $(\alpha h v)^{1 / 2}$ with hv for unexposed and exposed chitosan samples. Detected variations were observed at low photon energy. From the obtained results it may be thought that free radicals were formed and caused change

Egypt. J. Chem. 61, No.3 (2018) linked process, as mentioned before and previously reported by many researchers [30-32]. Figure 9 shows the dependence of $\ell n \alpha$ on the photon energy $(h v)$ of chitosan powder before and after exposure to UV-ozone for different doses. The observed curves indicated that the absorption did not follow the quadratic relation for interband transitions which did not verify Urbach rule [33]: $\alpha=\alpha_{0} \exp$ $h v / E_{b}$ where $\alpha_{o}$ is a constant, $v$ is the frequency of radiation and $E_{b}$ is the band tail energy value. The obtained data meant that chitosan has a semicrystalline nature as a polymeric material.

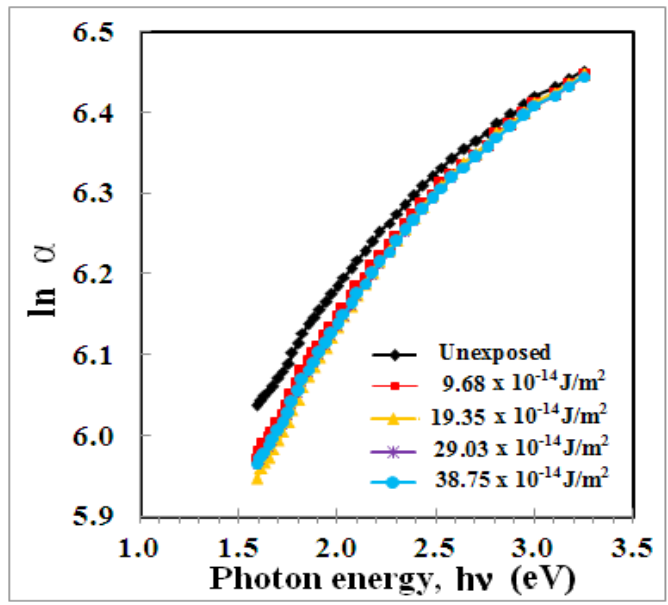

Fig. 9. Dependence of $\ell \mathbf{n} \alpha$ on hv of chitosan powder before and after exposure to UV-ozone.

in molecular configuration of chitosan which leads to the breakdown of the bonds followed by production of molecular structural changes in the chitosan system [30,31]. Aslo, the detected change in $E_{d}$ value was irregular which arised due to the variation in the total number available states caused by UV-ozone irradiation according to the compromise between the degradation and crosslinking processes [36].

The optical properties of polymeric material to light could be determined by calculating its extinction coefficient $(\mathrm{K})$ which characterized the photonic material and can be calculated using the following formula [46]: $\mathrm{K}=\alpha \lambda / 4 \pi$, where $\alpha$ (in $\mathrm{cm}^{-1}$ ) is the absorption coefficient and $\lambda$ is the wavelength (in $\mathrm{cm}$ ). On another hand, the optical properties of polymeric material to light can also be determined by calculating the color strength $(\alpha / S)$ according to Kubelka-Munk's equation [37]: $\alpha / S=(1-R)^{2} / 2 R$, where $S$ is the scattering coefficient and $\mathrm{R}$ is the reflectance value. Figure 12 displayed the variation in the extinction coefficient $(\mathrm{K})$ with the wavelength of unexposed 
and exposed chitosan samples. It was clear that, the variation behaviors of $\mathrm{K}$ for all samples were similar and their values increased with increasing the wavelength. On another hand, the values of $\mathrm{K}$ decreased with increasing the exposure dose up to $19.35 \times 10^{-14} \mathrm{~J} / \mathrm{m}^{2}$ and then increased with exposure dose up to $38.75 \times 10^{-14} \mathrm{~J} / \mathrm{m}^{2}$ but still less than the value of the unexposed sample. Besides, from the obtained data the extension coefficient values were in the order of $10^{-4}$ which indicated that unexposed chitosan sample was considered to be semi-crystalline material at room temperature and the crystallinity of the exposed samples change

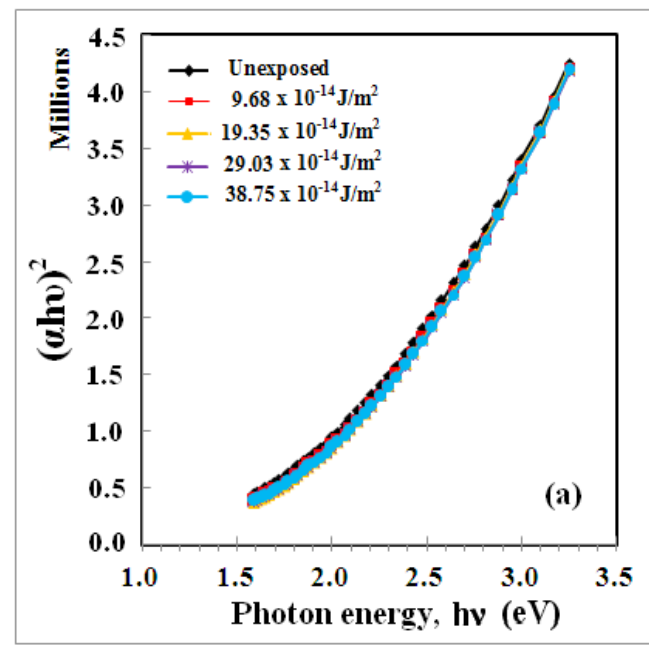

Fig.10. Plots of $(\alpha h v)^{2}$ against photon energy for chitosan powder before and after exposure to UV-ozone. due to the exposure to UV-ozone which indicates that fraction of light was lost due to scattering [38]. The dependence of the color strength $(\alpha / \mathrm{S})$ on wavelength $(\lambda)$ of chitosan powder before and after to UV-ozone with different doses was shown in Figure 13. It was clear from the figure that the values of color strength decreased by increasing the wavelength and the exposure dose. The observed decrease in $\alpha / \mathrm{S}$ values may be due to the fade of color and structure disorder in the chitosan matrix of the exposed samples in comparison with the unexposed one which was in agreement with the pre-mentioned data of the color parameters.

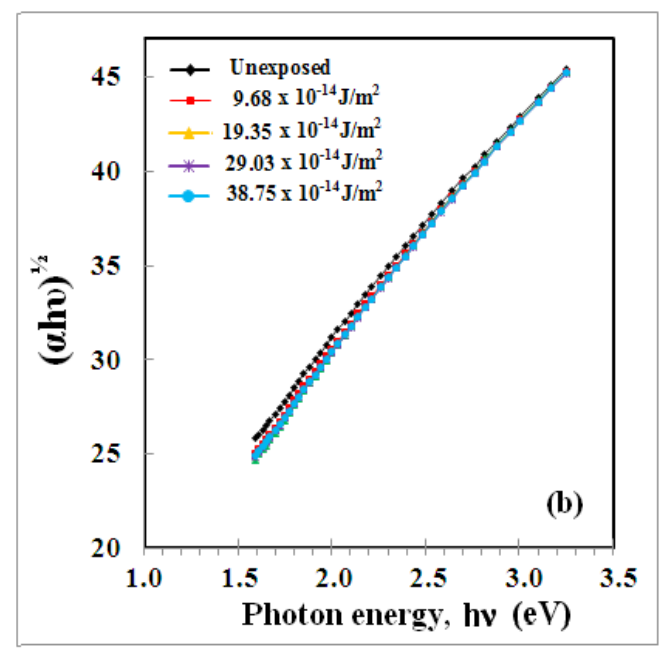

Fig. 11. Plots of $(\alpha h v)^{1 / 2}$ against photon energy for chitosan powder before and after exposure to UV-ozone.

TABLE 6. Variation in the value of allowed direct energy gap $\left(E_{d}\right)$ and its percentage changes for unexposed and exposed chitosan to UV-ozone.

\begin{tabular}{ccc}
\hline Exposure dose $\left(\mathbf{J} / \mathbf{m}^{2}\right)$ & $\mathbf{E}_{\mathbf{d}}(\mathbf{e V})$ & $\Delta\left(\mathbf{E}_{\mathbf{d}}\right) \%$ \\
\hline Unexposed chitosan & 2.2104 & - \\
$9.68 \times 10^{-14}$ & 2.0293 & 8.2 \\
$19.35 \times 10^{-14}$ & 2.0272 & 8.3 \\
$29.03 \times 10^{-14}$ & 2.0313 & 8.2 \\
$38.75 \times 10^{-14}$ & 2.0391 & 7.7 \\
\hline
\end{tabular}

\section{Conclusion}

Several modifications of chitosan as a biopolymer were required due to its extended applications in several fields. The microstructure, thermal and optical properties of UV-ozone exposed chitosan powder to different doses up to $38.75 \times 10^{-14} \mathrm{~J} / \mathrm{m}^{2}$ was analyzed. From the obtained data, it is concluded that, the exposed chitosan powder under investigation exhibited a radiation sensitization characteristic for each UV-ozone exposed dose. The microstructure analysis revealed that UV-ozone radiation produced different crystallinity compared to that of unexposed chitosan sample which may be due to significant interaction of UV-ozone irradiation 
with chitosan molecules. The more ordered arrangement was observed. Also, the thermal stability of exposed chitosan increased with increasing the exposure dose. On another hand, UV-ozone radiation induced photo-degradation of chitosan due to the cleavage of bonds in the main chain. The perceived variations in the optical parameters may be due to the occurrence changes in the physical bonds and in the molecular configuration of matrix. These differences indicate that formation of color centers in the polymeric system.

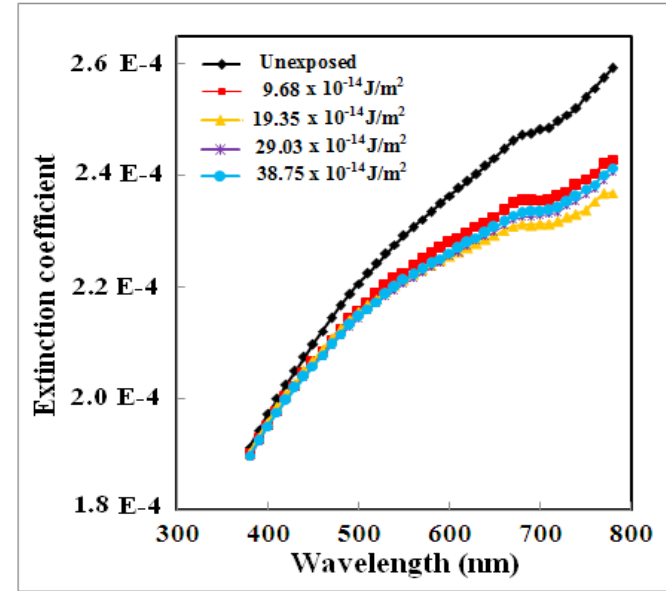

Fig. 12. Dependence of the extinction coefficient on wavelength for chitosan powder before and after exposure to UV-ozone.

\section{References}

1. He W. and Benson R., "Handbook of biopolymers and biodegradable plastics", A volume in Plastics Design Library (2013).

2. Osman E.M., Michael M.N. and Gohar H., The effect of both UV/ozone and chitosan on natural fabrics. International Journal of Chemistry, 2, 28 (2010).

3. Suljovrujić E., Ignjatović N., Uskoković D., Mitrić M., Mitrović M. and Tomić S., Radiation induced degradation of hydroxyapatite/poly L-lactide composite biomaterial. Radiation Physics and Chemistry, 76, 722 (2007).

4. Farrokhi-Rad M., Shahrabi T., Mahmoodi S. and Khanmohammadi Sh., Electrophoretic deposition of hydroxyapatite-chitosan-CNTs nanocomposite coatings. Ceramics International, 43, 4663 (2017).

5. Vo K.D.N., Kowandy C., Dupont L., Coqueret X. and Hien N.Q., Radiation synthesis of chitosan stabilized gold nanoparticles comparison between $\mathrm{e}^{-}$beam and $\gamma$ irradiation. Radiation Physics and Chemistry, 94, 84-87 (2014).

6. Park K.-.H, Kim S.-J., Lee W.-Y., Song H.-J. and Park Y.-J., Hydrothermal fabrication and characterization of calcium phosphate anhydrous/

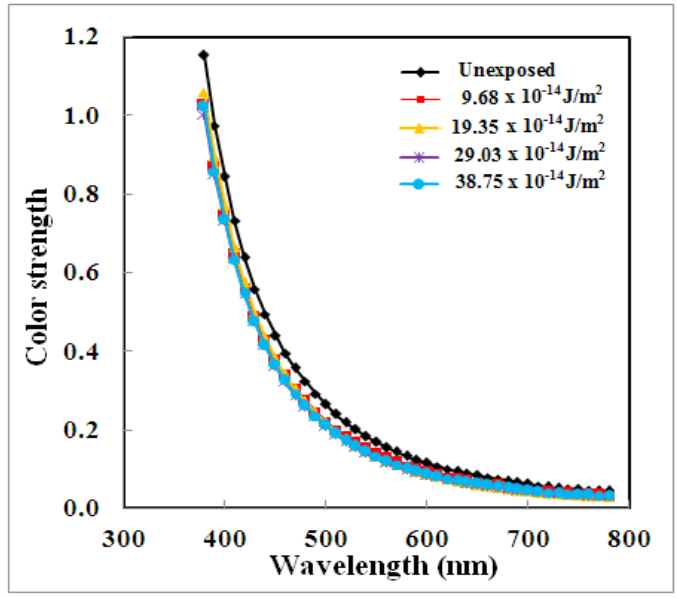

Fig.13. Dependence of the color strength on wavelength for chitosan powder before and after exposure to UV-ozone.

chitosan composites. Ceramics International, 43, 2786 (2017).

7. Rinaudo M., Chitin and chitosan: properties and applications. Progress in Polymer Science, 31, 603 (2006).

8. El Hadrami A., Adam L.R., El Hadrami I. and Daayf F., Chitosan in plant protection. Marine Drugs, 8, 968 (2010).

9. Moatary A., Teimouri A., Bagherzadeh M., Chermahini A.N. and Razavizadeh R., Design and fabrication of novel chitin hydrogel/chitosan/ nanodiopside composite scaffolds for tissue engineering. Ceramics International, 43, 1657 (2017).

10. Paul S., Jayan A., Sasikumar C.S. and Cherian S.M., Extraction and purification of chitosan from chitin isolated from, Sea Prawn (Fenneropenaeus indicus). Asian Journal of Pharmaceutical and Clinical Research, 7, 201 (2014).

11. Zhou Y.M., Gao B., Zimmerman A.R., Fang J., Sun Y.N. and Cao X.D., Sorption of heavy metals on chitosan-modified biochars and its biological effects. Chemical Engineering Journal, 231, 512 (2013).

12. Vijaya Y., Popuri S.R., Boddu V.M. and Krishnaiah 
A., Modified chitosan and calcium alginate biopolymer sorbents for removal of nickel (II) through adsorption. Carbohydrate Polymers, 72, 261 (2008)

13. Sionkowska A., Kaczmarek H., Wisniewski M., Skopinska J., Lazare S. and Tokarev V., The influence of UV irradiation on the surface of chitosan films. Surface Science, 600, 3775 (2006).

14. Matienzo L.J. and Winnacker S.K., Dry processes for surface modification of a biopolymer: Chitosan. Macromolecular Materials and Engineering, 287, 871 (2002)

15. Kumar M., Jeong H. and Lee D., Effect of UVozone plasma treatment on sol-gel-derived $\mathrm{HfO}_{2}$ thin films. Ceramics International, 43, 1174 (2017).

16. Sionkowska A., Planecka A., Lewandowska K. and Michalska M., The influence of UV-irradiation on thermal and mechanical properties of chitosan and silk fibroin mixture. Journal of Photochemistry and Photobiology B, 140, 301 (2014).

17. Martel-Estrada S.A., Santos-Rodríguez E., OlivasArmendáriz I., Cruz-Zaragoza E. and MartínezPérez C.A., The effect of radiation on the thermal properties of chitosan/mimosa tenuiflora and chitosan/mimosa tenuiflora/multiwall carbon nanotubes (MWCNT) composites for bone tissue engineering. AIP Conference Proceedings, 1607, 55 (2014).

18. Yasuda K., Okazaki Y., Abe Y. and Tsuga K., Effective UV/ozone irradiation method for decontamination of hydroxyapatite surfaces. Heliyon, 3, e 00372 (2017).

19. Robert M.S., Francis X.W., David J.K. and David L.A., "Spectrometric Identification of Organic Compounds", $8^{\text {th }}$ Edition, John Wiley \& sons Inc. New York (2015).

20. CIE 15 Technical Report on Colorimetry, third ed., International Commission on Illumination, USA (2004).

21. Guirguis O.W., El-Bassyouni G.T., Esawy M.A., Abd Elkader N.R., Mahmoud H.M., Mostafa H.M and Abdel-Zaher N.A., Exposure of chitosan to UV/ozone: structural information and antibacterial activity. Journal of Applied Pharmaceutical Science, 6, 124 (2016).

22. Jayakumar S., Sudha P.N., Subashini R., Gomathi T. and Latha S., The structure and the properties of chitosan/nylon 6/polyurethane ternary blends. International Journal of Scientific and Research Publications, 3, 1 (2013).

23. Corazzari I., Nisticò R., Turci F., Faga M.G., Franzoso F., Tabasso S., et al., Advanced physicochemical characterization of chitosan by means of TGA coupled on-line with FTIR and GCMS: Thermal degradation and water adsorption capacity. Polymer Degradation and Stability, 112, 1 (2015).

24. Madhu Mohan V., Raja V., Sharma A.K. and Narasimha Rao V.V.R., Ionic conductivity and discharge characteristics of solid-state battery based on novel polymer electrolyte (PEO + $\left.\mathrm{NaBiF}_{4}\right)$. Materials Chemistry and Physics, 94, 177 (2015).

25. Sakellariou P., Hassan A. and Rowe R.C., Phase separation and polymer interactions in aqueous poly(vinyl alcohol)/hydroxypropyl methylcellulose blends. Polymer, 34, 1240 (1993).

26. Lin K.-L., Phase identification using series of selected area diffraction patterns and energy dispersive spectrometry within TEM. Microscopy Research, 2, 57 (2014).

27. Fultz B. and Howe J.M., "Transmission Electron Microscopy and Diffractometry of Materials", Springer, Berlin (2013).

28. Abdel-Zaher N.A., Moselhey M.T.H. and Guirguis O.W., Effect of fast neutrons on the structural and thermal properties of poly(vinyl alcohol) and hydroxypropyl methyl cellulose blends. Journal of Thermal Analysis and Calorimetry, 126, 1289 (2016).

29. Katugampola P., Winstead C. and Adeleke A., Thermal stability of carboxymethyl chitosan varying the degree of substitution. International Journal of Pharmaceutical Science Invention, 3 , 42 (2014).

30. Miller A., "Handbook of Optics", Vol. 1, McGrawHill, New York, USA (1994).

31. Guirguis O.W. and Moselhey M.T.H., Optical study of poly(vinyl alcohol)/hydroxypropyl methylcellulose blends. Journal of Materials Science, 46, 5775 (2011).

32. Abd El-Kader F.H., Gaafer S.A. and Abd El-Kader M.F.H., Characterization and optical studies of 90/10 (wt/wt\%) PVA/b-chitin blend irradiated with $\gamma$-rays. Spectrochimica Acta Part A: 
Molecular and Biomolecular Spectroscopy, 131, 564 (2014)

33. Mott N.F. and Davis E.A., "Electronic Processes in Non-Crystalline Materials", Oxford, Clarendon (1979).

34. Tintu R., Saurav K., Sulakshna K., Nampoori V.P.N., Radhakrishnan P. and Sheemu Thomas., $\mathrm{Ge}_{28} \mathrm{Se}_{60} \mathrm{Sb}_{12} / \mathrm{PVA}$ composite films for photonic applications. Journal of Non-oxide Glasses, 2, 167 (2010).

35. Wood D.L. and Tauc J., Weak absorption tails in amorphous semiconductors. Phys. Rev. B, 5, 3144 (1972).
36. Chikwenze R.A. and Nnabuchi M.N., Effect of deposition medium on the optical and solid state properties of chemical bath deposited CdSe thin films. Chalcogenide Letters, 7, 389 (2010).

37. Judd D.B. and Wyszecki G., "Color in Business Science and Industry”, $3^{\text {rd }}$ Edition, John Wiley \& sons, Inc., New York (1975).

38. Pankove J.I., "Optical Process in Semiconductors", Devers Publication, New York, USA (1975).

(Received 19/2/2018; accepted 15/5/2018)

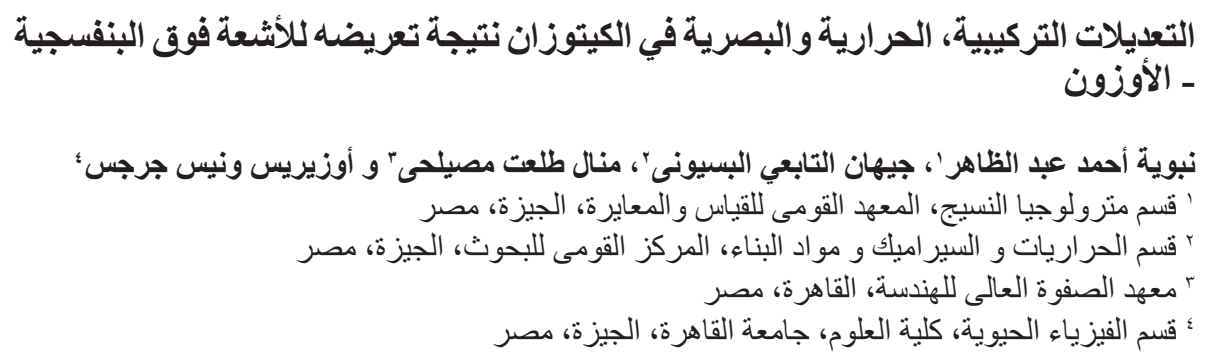

هدفت الدراسة الى تعديل تركيب الكيتوزان لما له من اماكن ملحوظة في الابحاث المتقدمة. تم دراسة نأثثير

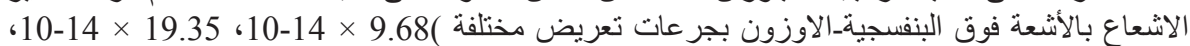

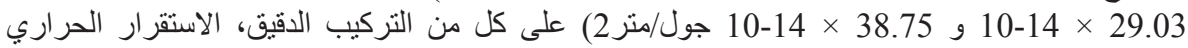

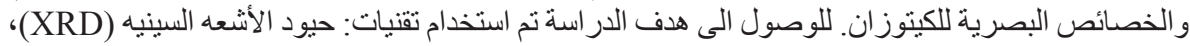

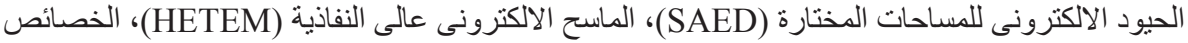

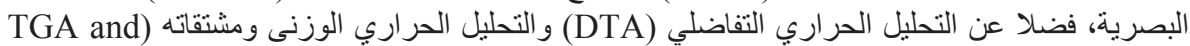
(DTG TGA وXRD، SAED، HETEM، DTA

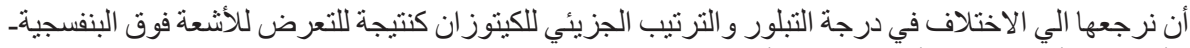

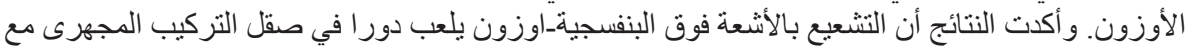

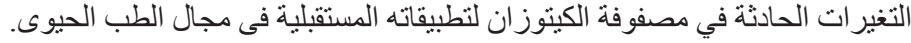

